\title{
JOURNAL.RU
}

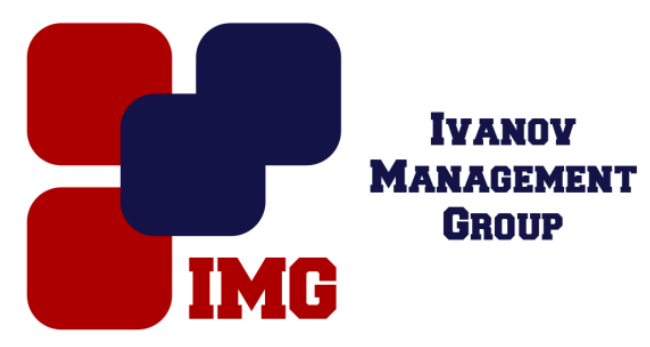

Понявина М.Б.

Финансовый университет при Правительстве Российской Федераџии Москва, Россия

doi: 10.18411/lj-30-06-2017-27

idsp 000001:1j-30-06-2017-27

\section{Актуальные аспекты государственной образовательной политики Республики Корея}

\begin{abstract}
Аннотация
Статья рассматривает вопросы взаимосвязи системы образования страны с ее экономическим развитием. Стремительное экономическое развитие Республики Корея наглядно демонстрирует четкую взаимозависимость роста уровня образования граждан с одновременным повышением благосостояния страны.

Ключевые слова: Политическая власть, Южная Корея, государственная образовательная политика, политическая культура, массовое политическое сознание, образовательная система
\end{abstract}

\section{Abstract}

The article examines the relationship of the educational system of the country with its economic development. The rapid economic development of the Republic of Korea demonstrates a clear relationship between growth of educational level of its citizens while improving the welfare of the country.

Keywords: Political power, South Korea, education policy, political culture, mass political consciousness, educational system

Структурно система образования Кореи является аналогом большинства образовательных систем мира, учитывая национальные особенности этой страны. Общая структура системы образования Республики Кореи состоит из 2 
лет дошкольного образования, шестилетнего начального образования, трехлетнего среднего образования, трехлетнего среднего образования в школах повышенной ступени, четырехлетнего образования в вузах. Существуют также профессионально-технические колледжи. При этом обязательными ступенями корейской системы образования являются начальное образование и трехлетнее среднее образование.

Министерство образования науки и техники Республики Кореи полностью контролирует все высшие учебные заведения, включая частные. Под контролем этого ведомства находятся все вопросы, связанные с образованием в стране: количество контингента, перечень учебных дисциплин, количество мест по каждой специальности, идеологическое соответствие образования. Управление системой образования осуществляется центральными и местными органами власти.

Финансирование образования Кореи осуществляется преимущественно за счет частного сектора, уровень которого является одним из самых высоких в странах ОЭСР. Начиная с 2013 года в Корее принято решение по увеличению доли затрат на образование всех уровней.

Государственная образовательная политика Кореи направлена на обеспечение высокого качества образования, а также необходимое количество специалистов в определенных сферах народного хозяйства. Эта установка подтверждается результатами международных исследований. Так, согласно тестам PISA 2012г., Корея показала одни из лучших результатов среди странОЭСР по математике, чтению и науке среди 15 летних школьников. Корея имеет одни из самых высоких показателей уровня успеваемости среди обучающихся в странах ОЭСР в области среднего и высшего образования.

В 2013 году Корея представила Национальные стандарты компетентности для определения и стандартизации образовательных компетенций. Новая учебная программа, основанная на национальных стандартах, была введена учебными заведениями Кореи.

Образование в Корее имеет очень высокую общественную значимость, что представляет собой фактор высокого спроса на обучение в вузах, в свою очередь, повышая востребованность дополнительного образования, преимущественно частного.В Корее 98\% населения возраста 25-34 имеют среднее образование, а 69\% - высшее. Высокой посещаемостью отличаются и дошкольные учреждения - 89\% 2-летних и 90\% трехлетних детей обучаются в Корее. Учебная программа в этих учреждениях оплачивается государством. 
Способность системы образования страны эффективно развивать навыки и перспективы рынка труда может сыграть важную роль в образовательных и профессиональных решениях ее населения. Молодые корейцы (в возрасте от 16 до 24 лет) были одними из лучших в области грамотности и счета в Обзоре навыков взрослого населения 2012 года. [4]

Несмотря на то, что согласно статистике, уровень безработицы в Корее является низким по сравнению со многими другими странами ОЭСР, возможности трудоустройства и доходы сильно варьируются в зависимости от уровня образования, степени престижности посещаемой школы и области обучения. Показатели отсутствия активности на рынке труда являются одними из самых высоких в ОЭСР: 20\% получивших высшее образование не могли найти работу в течение года после окончания вуза. При этом уровень занятости лиц с более низким уровнем образования выше среднего уровня стран ОЭСР.

Современная государственная образовательная политика Кореи привела к созданию одной из самых технологически передовых систем образования мира. В стране создана прогрессивная цифровая образовательная среда, разработан первый в мире электронный учебник[3], корейские школьники регулярно побеждают на международных соревнованиях компьютерной грамотности.

Южная Корея за последние четыре десятилетия продемонстрировала невероятные темпы экономического роста и глобальной интеграции для того чтобы стать высокотехнологичной индустриальной экономикой. В 1960-х годах ВВП на душу населения был сопоставим с уровнями беднейших стран Африки и Азии. В настоящее время Республика Корея представляет собой развитое государство с высокими экономическими показателями отдельных передовых отраслей. К примеру, корейское судопроизводство составляет $45 \%$ мирового рынка.

Данный результат, имеющий определяющее значение для страны и ее мирового положения, стал возможен исключительно благодаря грамотной и эффективной государственной образовательной политики, результаты которой и позволили Корее добиться таких существенных мировых показателей. 
1. Белова Т.А., Струкова М.И., Система образования в Южной Корее периода VI Республики. Вестник Нижегородского университета им. Н.И. Лобачевского, 2015, № 3, с. 9-18

2. Лузянин С.Г. и др. 2013. Корея: уроки истории и вызовы современности. Москва: ИДВ PAH. 413c.

3. Broadband Korea: Internet case study. http://www.itu.int//TUD/ict/cs/korea/material/CS_KOR.pdf

4. OECD (2016), Education Policy Outlook: Korea: www.oecd.org/education/policyoutlook.htm 